\title{
Distribuição vertical de Crysodeixis includens (Lepidoptera: Noctuidae) em cultivar transgênica e convencional de algodoeiro
}

\author{
Vertical distribution of Crysodeixis includens (Lepidoptera: Noctuidae) in transgenic and \\ conventional cotton cultivars
}

\section{Marina Funichello ${ }^{4 *}$, Diego Felisbino Fraga ${ }^{2}$, Evandro Pereira Prado ${ }^{3}$, Oniel Jeremias Aguirre-Gil ${ }^{4}$ \& Antonio Carlos Busoli ${ }^{4}$}

\author{
${ }^{1}$ Faculdade de Tecnologia, Presidente Prudente, SP, Brasil. *Autor para correspondência: mfunichello@gmail.com. \\ ${ }^{2}$ Faculdades Associadas de Uberaba, Uberaba, MG, Brasil. \\ ${ }^{3}$ Universidade Estadual Paulista, Dracena, SP, Brasil. \\ ${ }^{4}$ Universidade Estadual Paulista, Jaboticabal, SP, Brasil.
}

Submissão:18/08/2017 / Aceite: 24/04/2018

\begin{abstract}
RESUMO
O objetivo deste estudo foi avaliar a distribuição intra-planta de lagartas de Crysodeixis includens no cultivar convencional FM 993 e na sua isolinha transgênica FM 975 WS (WideStrike), que expressa as proteínas tóxicas Cry1Ac e Cry1F. O experimento foi realizado com o delineamento em blocos casualizados em esquema de parcelas subdivididas, com seis tratamentos (três terços da planta $\mathrm{x}$ duas faces foliares) e 40 repetições. As plantas foram visualmente divididas em três terços (superior, médio e inferior) e nas faces adaxial e abaxial das folhas, registrando-se o número de lagartas. Lagartas de $C$. includens foram identificadas em maior número no cultivar não-Bt (FM 993), enquanto que, na cultivar transgênica FM 975 WS (WideStrike), foram constatadas apenas as pequenas, em número significativamente menor que na sua isolinha não-Bt (FM 993). As lagartas, independentemente do tamanho e do cultivar, foram mais encontradas na parte inferior e mediana do dossel das plantas e, ainda, na face abaxial das folhas.
\end{abstract}

PALAVRAS-CHAVE: distribuição intra-planta, Gossypium hirsutum, lagarta falsa-medideira.

\begin{abstract}
The aim of this study was to evaluate the intra-plant distribution of Crysodeixis includens in conventional FM 993 and transgenic FM 975 WS (WideStrike), which express the toxic proteins Cry1Ac and Cry1F. The experiment was carried out in a split-plot design arranged under a complete block design with six treatments (three thirds $x$ two plant leaf surface) and 40 repetitions. The plants were visually divided into three thirds (upper, middle and lower) and into adaxial and abaxial leaves, registering the number of caterpillars. C includens caterpillars were found at higher numbers in the non-Bt cultivar (FM 993), while in the transgenic cultivar FM 975 WS (WideStrike) were found only small caterpillars, and significantly fewer compared to their non-Bt isoline (FM 993). Caterpillars, regardless of size and cultivar, were most commonly found at the bottom and middle thirds of the plant canopy and on the abaxial leaf surface.
\end{abstract}

KEYWORDS: intra-plant distribution, Gossypium hirsutum, looper caterpillar.

No agroecossistema algodoeiro ocorrem diversas espécies de insetos-praga, principalmente pertencentes à ordem Lepidoptera, os quais podem provocar prejuízos econômicos caso não sejam adotadas medidas de controle. Dentre tais pragas, encontra-se a Chrysodeixis includens Walker 1857, que vem causando danos significativos na cultura do algodoeiro, nos últimos anos, no Centro-Oeste do Brasil. Devido ao fato dos produtores dessa região terem visto no algodoeiro uma alternativa para rotação e plantio sucessivo com outras culturas economicamente importantes, como após a soja precoce (FONTES 2006), essa praga tem causado danos consideráveis nesse tipo de cultura.

O uso de inseticidas é a forma mais comum de controle dessa praga nas plantas de soja ou algodoeiro, no entanto tal prática pode acarretar prejuízos ao meio ambiente e à saúde humana, além de fazer com que populações se tornem mais resistentes a agroquímicos (MAIA 2005). Portanto, a transgenia 
surgiu como uma alternativa para minimizar os efeitos das pragas, devido à sua ação direta, específica e eficiente sobre elas. Atualmente, a utilização de genes oriundos da bactéria Bacillus thuringiensis tem sido adotada no processo de obtenção de plantas transgênicas.

A cultivar transgênica WideStrike ${ }^{\circledR}$ é geneticamente modificada por meio da sobreposição de genes, principalmente para produzirem, simultaneamente, as proteínas inseticidas Cry1F e Cry 1 Ac.

De um modo geral, os investimentos realizados para o controle de pragas na cultura do algodoeiro correspondem a proporções entre 25 e $30 \%$ do custo total de produção. Tal fato confere ao manejo de pragas um componente significativo na rentabilidade da cultura, de modo a ser decisivo para a obtenção de lucros na atividade (FREIRE 1997). Sob essa ótica, o conhecimento do agroecossistema, bem como de suas pragas, é fundamental dentro de um programa de Manejo Integrado de Pragas para a realização de uma amostragem segura e correta (BUSOLI et al. 2011).

Dessa forma, a realização de amostragens intra-plantas, também conceituada como distribuição vertical, tem como principal justificativa o fato de que se pode, por meio desse conhecimento, definir formas de agilizar e aumentar a confiabilidade do processo de amostragem de insetos em uma determinada cultura (FERNANDES et al. 2006). Logo, o objetivo deste trabalho foi avaliar a distribuição vertical de $C$. includens em cultivar transgênica e convencional de algodoeiro.

O experimento foi conduzido na Fazenda Alvorada, no município de Chapadão do Sul, MS, no ano agrícola de 2011/2012. Foram escolhidas duas áreas, uma com a cultivar transgênica FM 975 (WideStrike ${ }^{\circledR}$ ), outra com a sua isolinha convencional FM 993, que fazia parte da área de refúgio.

O delineamento experimental adotado foi em esquema de parcelas subdivididas, com seis tratamentos, sendo eles compreendidos de três terços das plantas (superior, médio e inferior) e as faces das folhas (abaxial e adaxial), com 40 repetições/blocos em cada área/cultivar. As repetições consistiam na avaliação minuciosa do número de lagartas encontradas nas folhas da planta inteira.

A avaliação do número de lagartas, em todo o dossel das plantas, foi realizada aos 55 dias após a emergência (DAE), quando as plantas se encontravam no estágio fenológico F2 (MARUR \& RUANO 2001), com a presença da praga em ambas cultivares. As plantas foram manual e cuidadosamente arrancadas a fim de evitar a queda das lagartas, imediatamente após o arranque, divididas visualmente em três terços (superior, médio e inferior). Para facilitar a contagem, as folhas foram destacadas, observando-se a presença de lagartas na superfície abaxial e adaxial delas. As lagartas foram separadas em três tamanhos: pequena (até $10 \mathrm{~mm}$ ); média (de 10 a $20 \mathrm{~mm}$ ); grande (acima de $20 \mathrm{~mm}$ ). Os resultados obtidos foram submetidos à análise de variância (ANOVA) pelo Teste $F$, sendo as médias comparadas pelo teste de Tukey ao nível de $5 \%$ de probabilidade.

$\mathrm{Na}$ distribuição vertical de lagartas de $C$. includens, nas plantas do cultivar convencional FM 993, os terços médios e inferiores das plantas foram os mais preferidos, verificando-se a presença de lagartas de todos os tamanhos (Tabelas 1 e 2 ).

Tabela 1. Número médio de lagartas de $C$. includens em diferentes terços das plantas e faces das folhas no cultivar convencional FM 993 e do cultivar transgênica FM 975 WS.

Table 1. Number of C. includens in different thirds of plants and leaf faces in cotton non-Bt FM 993 and Bt FM 975 WS.

\begin{tabular}{lll}
\hline & FM 993 & FM 975 WS \\
\hline Terço (T) & Média & Média \\
\hline Superior & $0,22 \mathrm{~b}$ & $0,05 \mathrm{a}$ \\
Médio & $0,57 \mathrm{a}$ & $0,02 \mathrm{a}$ \\
Inferior & $0,61 \mathrm{a}$ & $0,00 \mathrm{a}$ \\
\hline $\mathrm{F}(\mathrm{T})$ & $5,87^{* *}$ & $1,56^{\text {ns }}$ \\
\hline Face da folha (FF) & Média & Média \\
\hline Adaxial & $0,05 \mathrm{~b}$ & $0,00 \mathrm{~b}$ \\
Abaxial & $0,89 \mathrm{a}$ & $0,05 \mathrm{a}$ \\
\hline $\mathrm{F}(\mathrm{FF})$ & $66,00^{* *}$ & $4,68^{*}$ \\
\hline $\mathrm{CV}($ Terço) & 34,38 & 34,10 \\
$\mathrm{CV}(\mathrm{FF})$ & 37,42 & 34,10 \\
\hline Médias seguidas pela mesma letra na coluna não diferem entre si pelo teste de Tukey a 5\% de probabilidade. ${ }^{\text {ns }}$ não significativo
\end{tabular}

Médias seguidas pela mesma letra na coluna não diferem entre si pelo teste de Tukey a $5 \%$ de probabilidade. ${ }^{\text {ns }}$ não significativo

A interação entre os fatores terço das plantas e face das folhas, no cultivar FM 993, foi significativa, 
de modo que os terços médios e inferiores apresentaram o maior número de lagartas, quase que totalmente localizadas na face abaxial das folhas (Tabela 3).

Tabela 2. Número médio de lagartas pequenas, médias e grandes de $C$. includens presentes no cultivar convencional FM 993 e no cultivar transgênica FM 975 WS.

Table 2. Number of small, medium, and large C. includens in cotton non-Bt FM 993 and Bt FM 975 WS.

\begin{tabular}{cccc}
\hline \multicolumn{2}{c}{ Cultivar FM 993 } & \multicolumn{2}{c}{ Cultivar FM 975 WS } \\
\hline Tamanho & Média & Tamanho & Média \\
\hline Pequena & $1,72 \mathrm{a}$ & Pequena & $0,12 \mathrm{a}$ \\
Média & $0,70 \mathrm{~b}$ & Média & $0,00 \mathrm{~b}$ \\
Grande & $0,47 \mathrm{~b}$ & Grande & $0,00 \mathrm{~b}$ \\
\hline Teste F & $9,23^{* *}$ & & $4,04^{*}$ \\
\hline CV $(\%)$ & 40,82 & & 15,15 \\
\hline
\end{tabular}

Médias seguidas pela mesma letra na coluna não diferem significativamente entre si pelo teste de Tukey, a 5\% de probabilidade.

Tabela 3. Desdobramento da interação terços das plantas e faces das folhas no cultivar convencional FM 993.

Table 3. Splitting of interaction plant thirds and leaf faces in cotton non-Bt FM 993.

\begin{tabular}{lll}
\hline Terço & Adaxial & Abaxial \\
\hline Superior & $0,02 \mathrm{Aa}$ & $0,42 \mathrm{Ba}$ \\
Médio & $0,12 \mathrm{aB}$ & $1,02 \mathrm{Aa}$ \\
Inferior & $0,00 \mathrm{aB}$ & $1,22 \mathrm{Aa}$
\end{tabular}

Média seguidas pela mesma letra maiúscula, na linha, e minúscula, na coluna, não diferem entre si pelo teste de Tukey a $5 \%$ de probabilidade.

Embora o terço superior seja a região com maior presença de folhas novas e tenras, provavelmente, é a região onde as lagartas ficam mais expostas às condições adversas de fatores meteorológicos ou a predadores e parasitoides. As lagartas de $C$. includens alimentam-se de folhas localizadas no terço inferior das plantas, logo nos primeiros instares, selecionam as folhas mais tenras, alimentando-se daquelas com pequena quantidade de fibra (BUENO et al. 2009). No entanto, o fato desse inseto possuir hábito alimentar nas folhas do terço inferior e na superfície abaxial pode comprometer a eficiência de pulverizações com inseticidas, em virtude da dificuldade de as gotas transporem as folhas superiores e atingirem $o$ alvo desejado.

Em relação à oviposição das fêmeas de $C$. includens, JOST \& PITRI (2002) observaram que, na fase vegetativa das plantas, as fêmeas depositam seus ovos no terço superior do dossel, enquanto que, na fase reprodutiva da cultura, preferem depositar seus ovos no terço médio das plantas. Esses resultados corroboram os dados apresentados nesta pesquisa, onde os maiores números de lagartas foram verificados nas folhas do terço médio e inferior das plantas de algodão. A orientação dos insetos em relação às plantas deve-se ao fato de que elas transmitem odores que podem agir como estímulo para a orientação dos insetos (CHAPMAN 1998), e tais odores, provenientes de plantas, podem sofrer alterações dependendo do seu estágio fenológico (WERNER 1972).

Em relação ao número médio de lagartas de $C$. includens, nos diferentes terços das plantas no cultivar transgênica FM 975 WS (Tabela 1), observou-se que não houve diferença significativa entre os terços. No entanto, as poucas lagartas observadas também estavam na face abaxial das folhas, semelhante à sua isolinha comercial FM 993 (Tabela 1). Esses resultados, provavelmente, ocorram devido à alta eficiência de supressão de lagartas pela ação conjunta das proteínas Cry1Ac e Cry1F, sendo observadas, predominantemente, lagartas pequenas que ainda estavam se alimentando de tecidos foliares da referida cultivar e que não tinham morrido ainda. A proteína tóxica Cry1F age logo nos primeiros instares do desenvolvimento das lagartas (VIANA et al. 2014). Provavelmente, o fato do cultivar apresentar apenas lagartas pequenas, menores que $10 \mathrm{~mm}$ de comprimento, seja devido a esse fator.

FUNICHELLO et al. (2013), em trabalho com algodão transgênico que expressa a toxina Cry1Ac, observaram que as lagartas que sobreviveram à toxina apresentaram alterações nos parâmetros biológicos, como duração da fase larval do inseto, alongando-a e proporcionando menor massa corporal, em função do baixo consumo do alimento. VIANA et al. (2014) avaliaram os parâmetros biológicos de $C$. includens alimentadas com a cultivar de algodoeiro transgênica FM 975 WS e constataram que a expressão conjunta Rev. Ciênc. Agrovet., Lages, SC, Brasil (ISSN 2238-1171) 
das proteínas Cry1Ac e Cry1F causou 100\% de mortalidade de lagartas de primeiro instar.

Embora a cultivar transgênica FM 975 WS, evento conhecido comercialmente como WideStrike, tenha sido cultivada em grandes áreas pela primeira vez no ano agrícola de 2011/2012 no Centro-Oeste do País, pelos resultados levantados na presente pesquisa e por aqueles obtidos, no final da safra, pelos produtores de algodão, especialmente na Fazenda Alvorada, o emprego dessa cultivar foi eficiente na redução de populações de lagartas de $C$. includens, não sendo encontradas lagartas médias e grandes (Tabela 3). Não foram observadas injúrias de desfolhamento por essa praga, fato observado na isolinha convencional, onde foi necessária a utilização de pulverizações com inseticidas a fim de serem evitados danos econômicos provocados pela praga.

$\mathrm{Na}$ cultivar transgênica FM 975 WideStrike $^{\circledR}$, foram encontradas somente lagartas pequenas, em baixas densidades, nas partes medianas e inferiores das plantas, enquanto que, na cultivar FM 993, as lagartas de $C$. includens apresentavam-se em maiores quantidades nos terços médio e inferior das folhas, bem como localizadas na face abaxial das folhas. A localização das lagartas, na planta, é essencial para o Manejo Integrado de Pragas na cultura, facilitando a amostragem de pragas e diminuindo, assim, o uso indiscriminado de produtos químicos ou a aplicação de forma incorreta, os quais podem acarretar danos ao meio ambiente, resistência de pragas e maiores custos ao produtor.

\section{REFERÊNCIAS}

BUENO RCOF et al. 2009. Desempenho de tricogramatídeos como potenciais agentes de controle de Pseudoplusia includens Walker (Lepidoptera: Noctuidae). Neotropical Entomology 38: 389-394.

BUSOLI AC et al. 2011. Atualidades no MIP algodão no cerrado brasileiro. In: BUSOLI AC et al. (Ed.). Tópicos em Entomologia Agrícola IV. Jaboticabal: Multipress. p.117-138.

CHAPMAN RF. 1998. The insects: structure and function. 4.ed. Cambridge: Cambridge University. 770p.

FERNANDES MG et al. 2006. Distribuição vertical de lagartas de Alabama argillacea (Hubner) (Lepidoptera: Noctuidae) em plantas de algodão. Manejo Integrado de Plagas y Agroecología 78: 28-35.

FONTES EMG. 2006. The cotton agricultural context in Brazil. In: HILBECK A et al. (Eds.). Environmental risk assessment of genetically modified organisms: methodologies for assessing Bt cotton in Brazil. Wallingford: CABI Publishing. p.21-66.

FUNICHELLO M et al. 2013. Effect of transgenic and non-transgenic cotton cultivars on the development and survival of Psudoplusia includes (Walker) (Lepidoptera: Noctuidae). African Journal of Agriculture Research 44: 5424-5428.

FREIRE EC. 1997. Cultivares e produção de sementes na melhoria da qualidade do algodão no nordeste e CentroOeste do Brasil. Campina Grande: EMBRAPA. Disponível em: http://www.icac.org/cotton_info/tis/biotech/documents/ recorderdocs/march_04.pdf. Acesso em: 20 mai. 2012.

JOST DJ \& PITRE HN. 2002. Soybean Looper (Lepidoptera: Noctuidae) oviposition on cotton and soybean of different growth stages: Influence of olfactory stimuli. Journal of Economic Entomology 95: 286-293.

MAIA AHN. 2005. Definindo estratégias de manejo da resistência de pragas a toxinas Bt expressas em culturas transgênicas: o papel dos modelos de simulação. Disponível em: http://www.agencia.cnptia.embrapa.br/Repositorio/ Maia_definindoID-gLUEDBF8lh.pdf. Acesso em: 10 mai. 2012.

MARUR CJ \& RUANO OA. 2001. A reference system for determination of developmental stages of upland cotton. Revista de Oleaginosas e Fibrosas 5: 313-317.

VIANA DL et al. 2014. Parâmetros biológicos da lagarta falsa-medideira em cultivares de algodoeiro com as proteínas Cry1Ac e Cry1F. Pesquisa Agropecuária Brasileira 49: 569-572.

WERNER RA. 1972. Aggregation behaviour of the beetle Ips grandicollis in response to host-produced attractants. Journal of Insect Physiology 18: 423-437. 